\title{
What do doctors really think about the relevance and impact of GP appraisal 3 years on? A survey of Scottish GPs
}

Iain Colthart, Niall Cameron, Brian McKinstry and David Blaney

\begin{abstract}
Background

The aim of appraisal is to provide an opportunity for individuals to reflect on their work to facilitate learning and development. Appraisal for GPs has been a contractual requirement since 2004 in Scotland, and is seen as an integral part of revalidation.
\end{abstract}

Aim

To investigate the outcomes of GP appraisal in terms of whether it has prompted change in medical practice, education and learning, career development, attitudes to health and probity, how GPs organise their work, and their perception of the overall value of the process.

Design of study

A cross-sectional postal questionnaire.

Setting

GP performers in Scotland who had undertaken appraisal.

\section{Method}

The questionnaire was based on the seven principles outlined in Good Medical Practice, a literature review, and previous local research. The survey was conducted on a strictly anonymous basis with a random, representative sample of GPs.

\section{Results}

Fifty-three per cent (671/1278) responded. Forty-seven per cent (308/661) thought that appraisal had altered their educational activity, 33\% (217/660) reported undertaking further education or training as a result of appraisal, and 13\% (89/660) felt that appraisal had influenced their career development. Opinion was evenly split on the overall value of appraisal.

\section{Conclusion}

Appraisal can have a significant impact on all aspects of a GP's professional life, and those who value the process report continuing benefit in how they manage their education and professional development. However, many perceive limited or no benefit. The renewed emphasis on appraisal requires examination of these findings and discussion of how appraisal can become more relevant.

Keywords

appraisal; continuing education; general practitioners; professional education; revalidation.

\section{INTRODUCTION}

The requirement to undergo an annual appraisal became a contractual obligation for all UK GPs following the implementation of the new GP contract in April 2004. The Scottish GP Appraisal Scheme was instituted in January 2003, details of which are published elsewhere. ${ }^{1}$ The aims of the process reflected the statement of the Chief Medical Officer in 1999 when he advocated the introduction of an appraisal process for doctors that was not primarily concerned with detecting underperformance but would help them consolidate and improve on good performance. ${ }^{2}$ While feedback about experience of the process is routinely gathered following the appraisal, this study aimed to move beyond this limited feedback by evaluating the process in terms of the perceived impact in a number of important areas of a doctor's professional life.

Previous research on GP appraisal has focused on its acceptability to the participants. ${ }^{3-6}$ Although largely positive, concerns exist about the degree of engagement with the process of peer appraisal, with some evidence of collusion and evasion. ${ }^{7}$ However, the development of a structured appraisal process in

I Colthart, MA, research officer; D Blaney, MMed, EdD, FRCPE, FRCGP, director of postgraduate GP education, NHS Education for Scotland, Edinburgh. N Cameron, MPhil, FRCGP, DRCOG, national appraisal adviser, NHS Education for Scotland, Glasgow. B McKinstry, MD, FRCPE, FRCGP; senior research fellow, Division of Community Health Sciences, General Practice Section, University of Edinburgh, Edinburgh Scotland.

Address for correspondence

Mr Iain Colthart, NHS Education for Scotland, The Lister,

11 Hill Square, Edinburgh, EH8 9DR.

E-mail: iain.colthart@nes.scot.nhs.uk

Submitted: 6 July 2007; Editor's response: 11 September 2007; final acceptance: 10 December 2007.

(c)British Journal of General Practice 2008; 58: 82-87. DOI: 10.3399/bjgp08X264036 
medicine has been examined and demonstrated to have significant benefit on the delivery of care in a hospital setting. ${ }^{8}$

Research has attempted to predict the impact of possible outcomes for GPs following appraisal. ${ }^{9}$ As the Scottish appraisal system was designed to be consistent with Good Medical Practice,$^{10}$ this research went further and asked GPs what impact they felt appraisal had had on their medical practice, education and learning, career development, attitudes to health and probity, and how they organise their work. In addition, their opinions were sought on the overall value of the process.

The research was undertaken shortly after the publication of the review of professional regulation, Good Doctors, Safer Patients, ${ }^{11}$ undertaken by the Chief Medical Officer for England. The resulting white paper Trust, Assurance and Safety proposes fundamental changes to the current model of appraisal, and it is appropriate to examine what impact the existing model of appraisal is perceived to have had in these areas. ${ }^{12}$

\section{METHOD}

A random $25 \%$ sample, stratified by a health board, of all 4926 Scottish GPs who had undergone appraisal since 2004 was drawn from the Scottish appraisal database, using random number tables. A one in four sample was chosen as sufficient to detect important differences between age groups and regions, based on an assumed $50 \%$ response rate to the questionnaire. The complete populations in smaller health boards (Borders, Orkney, Shetland, and Western Isles) were sampled to increase the likelihood of a good response rate in these areas, giving a total sample of 1278 .

The survey was conducted on a strictly anonymous basis. Each GP was sent a postal questionnaire in September 2006 and one reminder 3 weeks later. An online version of the questionnaire was posted on the Scottish appraisal website, ${ }^{13}$ as a means of generating additional responses. It was recognised that there was a possibility of online responses duplicating postal responses, but it was thought this was unlikely to have a significant effect.

To enable returns to be monitored for a subsequent reminder exercise, a reply-paid postcard containing an address label was included with the survey. The postcard was returned separately to confirm completion of the survey. This allowed identification of non-responders, and a reminder to be sent.

\section{Creating the questionnaire}

The questionnaire was based on the seven principles of good practice as outlined by the General Medical Council in Good Medical Practice, ${ }^{10}$ a literature review, and a previous internal NHS Education for Scotland

\section{How this fits in}

Previous research in appraisal has focused on process issues and showed general satisfaction with the system. There has been research on the predicted impact of appraisal but none evaluating actual perceived outcomes. This study provides evidence that GPs perceive that appraisal has had a varying impact on important outcomes, based on the seven principles of Good Medical Practice.

report on significant issues raised in GP appraisal in Scotland. ${ }^{14} \mathrm{~A}$ pilot version of the questionnaire was tested with a convenience sample of $20 \mathrm{GPs}$ and local appraisal advisers. This led to several iterations of the survey before a final version was created. A machinereadable survey form (Appendix 1) was created using TeleForm ${ }^{\circledast}$ software. Data were verified and validated by a dedicated e-forms team, before being exported into Microsoft ${ }^{\circledast}$ Excel and SPSS 15.0 for Windows for analysis.

\section{RESULTS}

\section{Response rate}

A total of $671 / 1278$ (53\%) responses were received, including 14 online responses. The response rate was broadly comparable to other such studies. ${ }^{15} \mathrm{~A}$ comparison of the distribution of responders by age, sex, and health board with statistics from the Scottish Information Services Division ${ }^{16}$ suggests these were representative of the Scottish GP population.

\section{Profile of responders}

The distribution of responders by practice type was representative of Scottish general practice. Most worked full-time $(61 \%, 400 / 660)$, with $34 \%$ part-time, $2 \%$ job share, and $3 \%$ having another working arrangement. Responders worked on average 7.2 clinical sessions a week, which is comparable to a recent Scottish GP workload study. ${ }^{17}$

\section{Number of appraisals}

Ninety-eight per cent $(658 / 671)$ had experienced at least one appraisal, $85 \%$ two appraisals, 30\% three appraisals, and $4 \%$ had undertaken four.

\section{Impact of the appraisal scheme on clinical practice}

The survey was designed to evaluate the perceived impact of the appraisal process on the elements defined in Good Medical Practice..$^{10}$ Responders were asked to indicate the degree of change they attributed to appraisal by choosing from five options: 'not at all'; 'in a small way'; 'a fair amount'; 'quite a lot'; and 'a great deal'. The data were examined both at an individual, component question level, and by group in terms of the seven main headings outlined in Good Medical Practice. 
Table 1. Change attributed at an individual question level.

\begin{tabular}{|c|c|c|c|}
\hline & Not at all (\%) & $\begin{array}{l}\text { In a small } \\
\text { way }(\%)\end{array}$ & $\begin{array}{l}\text { A fair amount, } \\
\text { quite a lot, and } \\
\text { a great deal (\%) }\end{array}$ \\
\hline \multicolumn{4}{|l|}{ Good clinical care } \\
\hline \multicolumn{4}{|l|}{ Has GP appraisal changed: } \\
\hline 1. Your prescribing? & 56.3 & 31.5 & 12.3 \\
\hline 2. Your record keeping? & 52.4 & 30.6 & 17.0 \\
\hline 3. Recognition of your limitations? & 34.7 & 39.4 & 26.0 \\
\hline 4. Reviewing referral patterns? & 44.2 & 34.4 & 21.4 \\
\hline 5. Communication with colleagues? & 51.1 & 29.0 & 19.9 \\
\hline \multicolumn{4}{|l|}{ Maintaining good medical practice } \\
\hline \multicolumn{4}{|l|}{ Has GP appraisal changed: } \\
\hline 6. Keeping professional knowledge up to date? & 31.1 & 33.0 & 35.9 \\
\hline 7. Keeping your professional skills up to date? & 34.1 & 33.0 & 32.9 \\
\hline 8. Taking part in educational activities? & 39.9 & 31.3 & 28.7 \\
\hline 9. Taking the lead in clinical audit? & 49.3 & 29.8 & 20.9 \\
\hline 10. Undertaking significant event analysis? & 27.9 & 27.8 & 44.3 \\
\hline 11. Identifying gaps in your knowledge? & 25.1 & 36.5 & 38.4 \\
\hline 12. How you incorporate evidence-based knowledge? & 38.1 & 34.2 & 27.7 \\
\hline \multicolumn{4}{|l|}{ Teaching and training } \\
\hline $\begin{array}{l}\text { 13. Has GP appraisal changed the contribution you make to the education } \\
\text { of registrars, students, or colleagues? }\end{array}$ & 47.4 & 36.9 & 15.7 \\
\hline 14. Has GP appraisal changed you in developing your skills as a teacher? & 51.5 & 32.7 & 15.7 \\
\hline \multicolumn{4}{|l|}{ Relationships with patients } \\
\hline 15. Has GP appraisal influenced you in developing your patient communication skills? & 59.7 & 29.8 & 10.5 \\
\hline 16. Has GP appraisal influenced you in reviewing the way you deal patient with complaints? & 49.8 & 32.7 & 17.6 \\
\hline \multicolumn{4}{|l|}{ Working with colleagues } \\
\hline \multicolumn{4}{|l|}{ Has GP appraisal changed: } \\
\hline 17. The way you communicate with colleagues? & 65.5 & 22.6 & 12.0 \\
\hline 18. Clarifying responsibilities in the team? & 60.7 & 24.2 & 15.1 \\
\hline 19. Being aware of the performance of colleagues? & 51.7 & 29.9 & 18.4 \\
\hline 20. Supporting other members of the team if performance issues occur? & 55.9 & 25.9 & 18.3 \\
\hline 21. Delegating care to other healthcare workers? & 62.5 & 22.9 & 14.6 \\
\hline \multicolumn{4}{|l|}{ Probity } \\
\hline 22. Has GP appraisal led you to consider how you account for your professional conduct? & 32.6 & 40.8 & 26.6 \\
\hline \multicolumn{4}{|l|}{ Health issues } \\
\hline 23. Has GP appraisal led you to think about your own health in the context of your job? & 56.1 & 30.1 & 13.8 \\
\hline $\begin{array}{l}\text { 24. Has GP appraisal prompted you to develop an understanding of what it means } \\
\text { to manage your own health? }\end{array}$ & 61.5 & 26.6 & 11.9 \\
\hline
\end{tabular}

Analysis of responses (Table 1) indicated that, for most items, the three 'higher' response options tended to be chosen relatively infrequently, responses being concentrated towards the lower end of the response scale (that is, 'not at all' and 'in a small way'). It was therefore decided to aggregate responses to the three higher options ('a fair amount', 'quite a lot', and 'a great deal') into a single composite category. This offered the incidental advantage of making the data easier to understand when presented in tabular form.

Examining the data at individual question level identified the specific areas where appraisal has had most and least influence. The main areas of impact were: in undertaking significant event analysis, identifying knowledge gaps, and keeping professional knowledge up to date. There was less impact perceived in the areas of communication with colleagues and patients, team management, and managing personal health.

Figure 1 summarises the reported change perceived by GPs on each of the seven sections of Good Medical Practice as represented by an average across all questions in each respective section. It illustrates that while appraisal has had most impact in the areas of 'maintaining good medical practice' and 'probity', one-third felt that it had no perceived impact, and less than one-fifth felt it had a discernible impact in the areas of 'working with colleagues', 'relationships with patients', and 'health'.

\section{Impact on GP education and learning}

Just under half of GPs $(46.6 \%, 308 / 661)$ thought that appraisal had altered the type of educational activity in which they had participated. The most commonly 


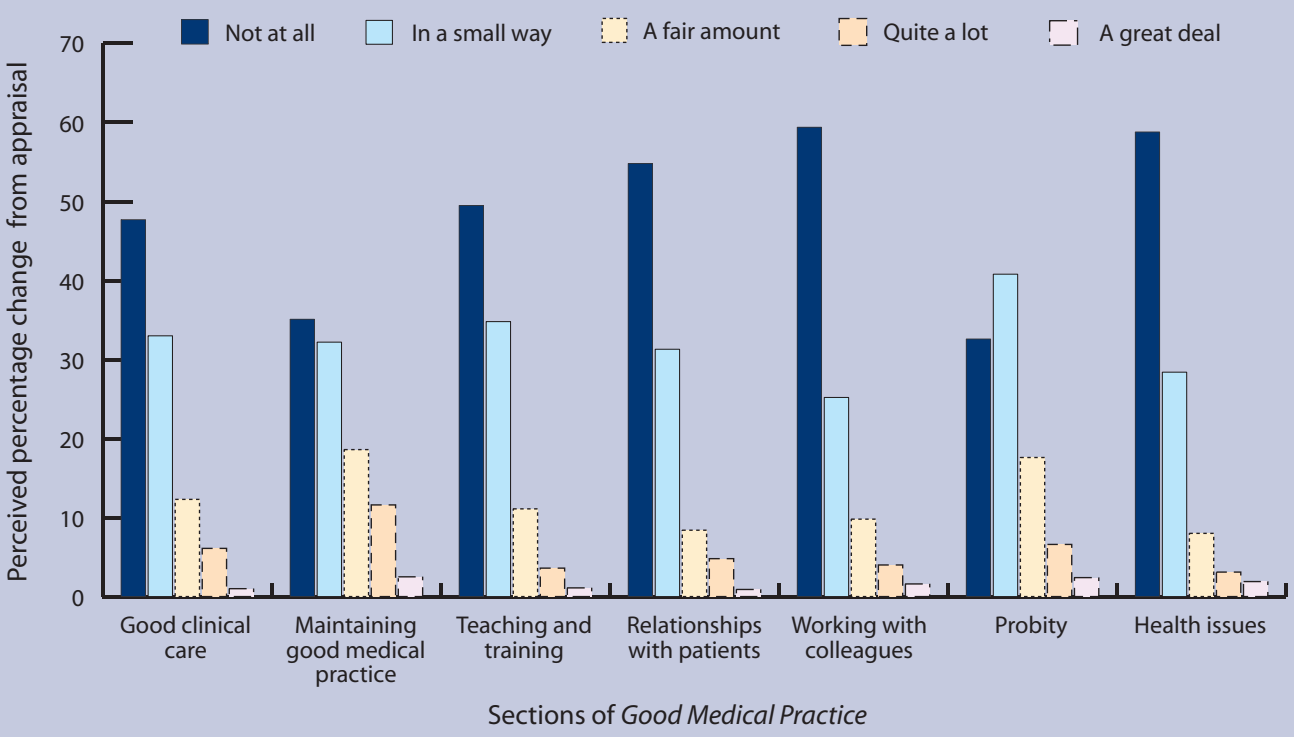

Figure 1. Comparison of distribution of percentage change resulting from appraisal averaged for all questions within each section of Good Medical Practice. $^{10}$

reported type of activity undertaken was e-learning $(34.6 \%, 232 / 671)$, followed by practice-based learning $(27.7 \%, 186 / 671)$, and protected learning time events (23.1\%, 155/671).

The introduction of appraisal was compared with a previous incentive to promote learning and development, the postgraduate educational allowance (PGEA). Approximately one-third (34.5\%, 225/653) felt that appraisal was more beneficial than PGEA, another third (31.4\% (205/653) preferred PGEA, with the remainder being neutral or unsure $(34.1 \%, 223 / 653)$.

A key component of the appraisal system is the creation of a personal development plan. There were mixed views on the role of personal development plans, with half of responders stating that they had influenced their learning $(49.6 \%, 324 / 653)$, and half indicating they had not $(50.4 \%, 329 / 653)$. Many of those influenced by personal development plans commented that they had provided them with focus, structure, and organisation.

The comments received describe a number of reasons for appraisal's impact on education and learning. A number of responders recorded that they were already engaged in many of the activities in the appraisal process prior to its introduction, and therefore had less scope to change. The introduction of the new contract is also likely to have been a significant factor in how GPs planned their development and the educational activities they undertook. Other responders bemoaned the lack of clarity surrounding the purpose of appraisal, and it is likely that this perception was heightened by the confusion surrounding the future of revalidation, and possibly reduced the level of engagement with appraisal. Some responders were suspicious of its true purpose, perceiving it as a summative process. This perception has persisted despite attempts to ensure clarity about the developmental ethos and purpose of appraisal. ${ }^{18}$

\section{Impact on career development}

Almost one-third of responders $(32.9 \%, 217 / 660)$ reported that they had undertaken further education or training directly as a result of appraisal, including acquiring new skills and knowledge such as undertaking IT training or a diabetes course.

Thirteen per cent (89/660) felt that appraisal had influenced their career development. Several described how they had undertaken additional activities such as becoming appraisers and trainers, but some had rationalised their activities by limiting the number of professional tasks and roles they undertook.

Eleven responders commented that the demands of appraisal had led them to bring forward their retirement plans.

\section{General impact of appraisal}

Thirty-nine per cent of GPs (257/664) stated that appraisal had prompted the introduction of new practice policies, procedures, and guidelines. It had less impact in changing the ways GPs managed their workload $(23.8 \%, 157 / 661)$ or managed patient consultations $(15.2 \%, 101 / 663)$.

Table 2. Perceived value of appraisal.

\begin{tabular}{lccccc} 
& $\begin{array}{c}\text { Extremely } \\
\text { valuable (\%) }\end{array}$ & Valuable (\%) & $\begin{array}{c}\text { Marginal } \\
\text { Value (\%) }\end{array}$ & No value (\%) & $\begin{array}{c}\text { Total } \\
\text { number }\end{array}$ \\
\hline First appraisal & 10.5 & 36.6 & 38.6 & 14.3 & 658 \\
\hline Second appraisal & 6.5 & 34.2 & 42.6 & 16.8 & 571 \\
\hline Third appraisal & 6.9 & 34.5 & 42.4 & 16.3 & 203
\end{tabular}

Note: no data are presented for the fourth appraisal due to limited numbers ( $n=24)$. 
The appraisal process had similar impact in changing responders feelings on their practice as an organisation $(22.4 \%, 148 / 662)$, and how they related to their colleagues $(22.6 \%, 150 / 663)$. Those who felt appraisal to be beneficial in this area commented that positive outcomes included improved team working, better awareness, communication, cohesion, and organisation within the practice, and a greater appreciation and understanding of their peers, for example their learning needs.

\section{Overall value of the appraisal system}

Opinion was evenly divided as to the perceived value of the appraisal process (Table 2). There is evidence that the value GPs attach to or derive from subsequent appraisals declines, but GPs who found the first appraisal valuable generally continued to do so, and those who did not also persisted in their view.

Spearman's rank correlation was used as an appropriate method to assess associations among ordered categorical variables. ${ }^{19}$ No correlation was found between GP status, age, sex, membership of the Royal College of General Practitioners, and perceived value of appraisal. In contrast, a positive association was found between perceived change in outcomes and value - those who rated appraisal as valuable or extremely valuable reported greater change in outcomes (Spearman's rank correlation ranged from 0.36 to 0.64 , all $P<0.001$ ).

\section{DISCUSSION}

\section{Summary of main findings}

These findings raise important issues for those who plan and deliver GP appraisal. The results demonstrate that appraisal can have a significant impact on a number of areas that support the development of GPS and facilitate learning. However, for many responders, participation in appraisal had either limited or no perceived impact on their learning and development.

Appraisal is considered by a significant number of GPs to be of particular value with regard to its impact on how they maintain their clinical skills and knowledge, and how they structure their education and plan their development. This is a key aim of GP appraisal and it is reassuring that a large number of doctors are benefiting in this way. However, given the extensive literature on the apparent inaccuracy of strategic self-assessment, ${ }^{20}$ there must be some doubts about the effects of this on actual clinical practice. However, this caveat might be equally applied to the ability to accurately assess the positive influence of interventions.

In other areas such as organisational issues and career development, appraisal had less impact, which may simply reflect that fewer responders had concerns in these areas. This may also be true for issues of personal health and probity. The reported extent of the impact on managing health reflects the view that a small but significant minority of GPs have personal health issues that have an impact or could have an impact on patient care. ${ }^{21}$ As such, these results can be interpreted as appropriate.

\section{Strengths and limitations of the study}

This is the first attempt to explore the impact as perceived by participating doctors of any GP appraisal scheme, beyond simple satisfaction with the process.

There are some limitations to the research. The nonresponse rate raises the question of generalisability, ${ }^{15}$ and potentially responders may have been more or less enthusiastic than the whole sample about appraisal. The survey relied on self-reporting by responders which was not triangulated with other data. Similarly, there are no other data to compare results against as this is the first research of this type. In terms of evaluating the effectiveness of appraisal, the study did not set out to judge the outcomes. It is difficult to evaluate outcome measures for perceived impact, which necessarily are aspirational. It is more appropriate to regard this study as providing a baseline for future research.

In terms of attribution, GPs may ascribe a change in behaviour to appraisal, while it may have happened anyway, in the absence of appraisal. For example, significant event analysis was a core category of appraisal in Scotland prior to its inclusion in the Quality and Outcomes Framework (QOF), and its inclusion in the QOF may have contributed to the level of uptake attributed to appraisal in this study. Similarly, other reported changes such as the increased use of elearning may simply reflect a general trend.

The Likert scale employed assumes no negative effect of appraisal on the participants. A negative to positive scale might have been more revealing. However, this was not considered necessary because of the largely positive literature about appraisal at the time of the study design.

\section{Comparison with existing literature}

Although there is comparatively little evidence of how education influences practice, ${ }^{22,23}$ it has been shown that targeted interventions and interventions that relate to clinical practice are most successful. ${ }^{24}$ The appraisal process employed a similar model, introducing a standard framework with explicit criteria relating to the seven areas of Good Medical Practice. However, this standardised approach may lack the necessary sophistication to address all individual learning styles and developmental needs, or to provide an appropriate level of challenge for all participants.

\section{Implications for future research}

The appraisal process has an undoubted cost in terms 
of time and resources. In Scotland it is recommended that the appraisal process should involve a session of preparatory time on behalf of both the appraiser and appraisee, with a further session devoted to completing the process. This represents the annual average workload of several GPs. The process also requires local and national administrative support. We owe it to patients and all other stakeholders to demonstrate that a process that impinges on time devoted to actual patient care is of value and can fulfil the aims of the appraisal process to promote the development of GPs. A first step to achieving this would be to open up a dialogue with all stakeholders to explore how the appraisal process could develop to have a greater impact on patient care, and how this might be achieved in a cost-effective manner. Similarly, this study did not set out to explore the pastoral aspect of appraisal, which is regarded by many as an implicit benefit of a developmental appraisal process. Significant potential exists to explore sensitive areas such as morale and the impact of complaints.

This research was undertaken prior to the publication of the white paper Trust, Assurance and Safety, ${ }^{12}$ which sets out a programme for reform of the regulation of health professionals. There is a clear indication that the appraisal process will require the inclusion of more objective evidence matching specified criteria with greater subsequent examination of the outcomes of appraisal. The results of this research indicate that appraisal can have an impact and benefit for GPs in all areas of their professional life. In some of the areas addressed, the reported limited impact may be entirely appropriate, and equally, other benefits may be unacknowledged, as exemplified by the Johari window model. ${ }^{25}$ However, the findings demonstrate that there is a clear requirement to attempt to ensure that appraisal becomes increasingly relevant for all GPs, that the links with professional regulation are clear, and that the resources it employs are used wisely. Further in-depth qualitative research has therefore been commissioned. It is hoped that this will answer many of the issues raised by this initial study to allow the appraisal process to build on the identified benefits.

\section{Funding body}

The study was funded by NHS Education for Scotland. Brian McKinstry is supported by the Chief Scientist Office of the Scottish Government (reference CZP/4/1)

\section{Ethical approval}

Ethical approval was not sought as it was not deemed necessary

\section{Competing interests}

Niall Cameron is the national appraisal adviser at NHS Education for Scotland (NES), which is responsible for administering GP appraisal in Scotland. lain Colthart and David Blaney are also employed by NES. The views expressed in the paper reflect those of the authors and not NES

\section{Acknowledgements}

We gratefully acknowledge Marjorie McArthur and Joyce McCrae for administrative support, Louise Cardno for form design and data management, Jeremy Walker for statistical guidance, and Murray Lough for helpful advice

\section{Discuss this article}

Contribute and read comments about this article on the Discussion Forum: http://www.rcgp.org.uk/bjgp-discuss

\section{REFERENCES}

1. Hunter C, Blaney D, McKinstry B, et al. GP appraisal: a Scottish solution. Educ Prim Care 2005; 16(4): 434-439.

2. Department of Health. Supporting doctors, protecting patients. London: Department of Health, 1999.

3. McKinstry B, Shaw J, McGilvray L, Skinner L. What do general practitioners think about annual appraisal? A questionnaire-based crosssectional study in southeast Scotland. Educ Prim Care 2002; 13(4): 472-476.

4. Jelley D, van Zwanenberg T. Peer appraisal in general practice: descriptive study in the Northern Deanery. Educ Gen Pract 2001; 11(1): 281-287.

5. Lewis M, Elwyn G, Wood F. Appraisal of family doctors: an evaluation study. Br J Gen Pract 2003; 53(491): 454-460.

6. Nayar V. A qualitative study of general practitioners' views of the appraisal process. Educ Prim Care 2005; 16(6): 672-679.

7. McKinstry B, Peacock H, Shaw J. GP experiences of partner and external peer appraisal: a qualitative study. Br J Gen Pract 2005; 55(516): 539-543.

8. West MA, Borrill C, Dawson J, et al. The link between the management of employees and patient mortality in acute hospitals. Int $\mathrm{J}$ Hum Resour Manage 2002; 13(8): 1299-1310.

9. Conlon M, Sweeney G, Lyons N, Shelly M. Appraisal: experiences, attitudes and impact. An evaluation of the appraisal process for general practitioners in England. Clinician in Management 2006; 14: 5-22.

10. General Medical Council. Good medical practice. London: General Medical Council, 2006

11. Department of Health. Good doctors, safer patients: proposals to strengthen the system to assure and improve the performance of doctors and to protect the safety of patients. London: Department of Health, 2006.

12. Department of Health. Trust, assurance and safety: the regulation of health professionals. London: Department of Health, 2007.

13. Scottish Online Appraisal Resource (SOAR). http://www.scottishappraisal.scot.nhs.uk (accessed 11 Dec 2007).

14. NHS Education for Scotland (NES). Report on the significant issues raised in GP Appraisal in Scotland 2003 - 2004. Edinburgh: NES, 2005.

15. Barclay S, Todd C, Finlay I, et al. Not another questionnaire! Maximizing the response rate, predicting non-response bias in postal questionnaire studies of GPs. Fam Pract 2002; 19(1): 105-111.

16. Information Services Division. General medical services workforce statistics. http://www.isdscotland.org/isd/information-andstatistics.jsp?pContentID $=3793 \&$ p_applic $=$ CCC\&p_service $=$ Content.sh ow\& (accessed 4 Jan 2008)

17. McKinstry B, Colthart I, Elliott K, Hunter C. The feminization of the medical workforce, implications for Scottish primary care: a survey of Scottish general practitioners. BMC Health Serv Res 2006; 6: 56.

18. NHS Education for Scotland (NES). Appraisal for general practitioners working in Scotland. Handbook for appraisers and appraisees. Edinburgh: NES, 2003.

19. Altman, D. Practical statistics for medical research. London: Chapman \& Hall, 1991.

20. Eva KW, Regehr G. Self-assessment in the health professions: a reformulation and research agenda. Acad Med 2005; 80(10 suppl): S46-54.

21. Sibbald B, Enzer I, Cooper C, et al. GP job satisfaction in 1987, 1990 and 1998: lessons for the future? Fam Pract 2000; 17(5): 364-371.

22. Davis DA, Thomson MA, Oxman AD, Haynes RB. Evidence for the effectiveness of CME. A review of fifty randomised controlled trials. JAMA 1992; 268(9): 1111-1117.

23. Davis DA, Thomson MA, Oxman AD, Haynes RB. Changing physician performance: a systematic review of continuing medical education strategies. JAMA 1995; 274(9): 700-705.

24. Cantillon $P$, Jones R. Does continuing medical education in general practice make a difference? BMJ 1999; 318(7193): 1276-1279.

25. Luft J. Of human interaction. Palo Alto CA: National Press, 1969. 
Appendix 1. Machine-readable survey form.

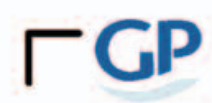

GP Appraisal Survey

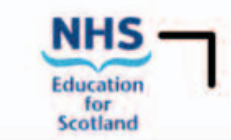

\section{You and Your Work}

1. What is your current GP status?

2. Are you:

3. What age are you?

4. Do you work in a training practice?

5. If you permanently work in a practice, what type?

6. What is your employment status?

\begin{tabular}{|c|c|c|c|}
\hline Principal & Salaried & Locum & Retainer \\
\hline
\end{tabular}

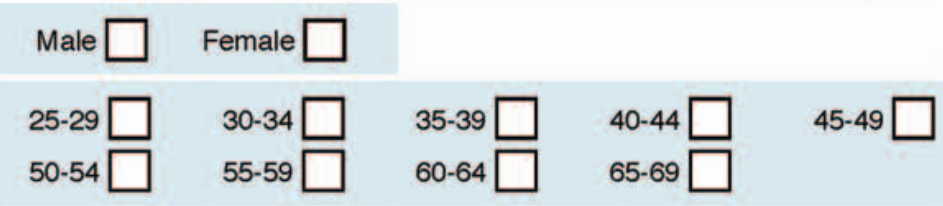

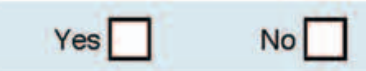

\begin{tabular}{|c|c|c|}
\hline Inner City & Urban & Suburban \\
\hline Rural & Isolated Rural & Not applicable \\
\hline
\end{tabular}

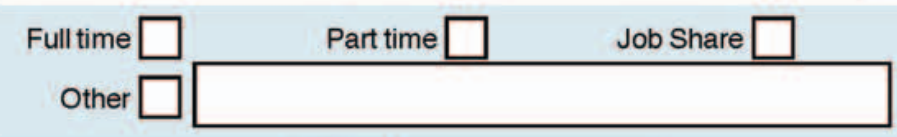

7. How many clinical sessions on average do you work a week? clinical sessions
8. Are you a member of the RCGP?
Yes $\square$
No $\square$

\section{Good Clinical Care}

9. Has the GP appraisal process changed the way you deliver clinical care in the following areas?
a) Prescribing
b) Record keeping
c) Recognising your limitations
d) Reviewing referral patterns
e) Communicating with colleagues
a lot

$\begin{array}{ll}\square & \square \\ \square & \square \\ \square & \square \\ \square & \square \\ \square & \square\end{array}$

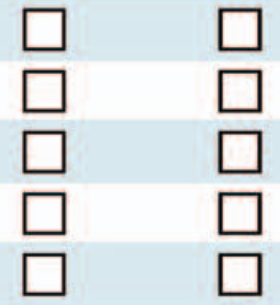

$\begin{array}{cccc}\text { Not } & \text { In a } & \text { A fair } & \text { Quite } \\ \text { at all } & \text { small way } & \text { amount } & \text { a lot }\end{array}$

\section{Maintaining Good Medical Practice}

10. Has appraisal changed the way you maintain good medical practice?

$\begin{array}{ccccc}\text { Not } & \text { In a } & \text { A fair } & \text { Quite } & \text { A great } \\ \text { at all } & \text { small way } & \text { amount } & \text { a lot } & \text { deal }\end{array}$
a) Keeping your professional knowledge up to date
$\square$
b) Keeping your professional skills up to date
c) Taking part in educational activities
d) Taking the lead in clinical audit
e) Undertaking Significant Event Analysis
f) Identifying gaps in your knowledge
g) How you incorporate evidence based knowledge

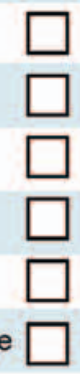

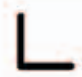
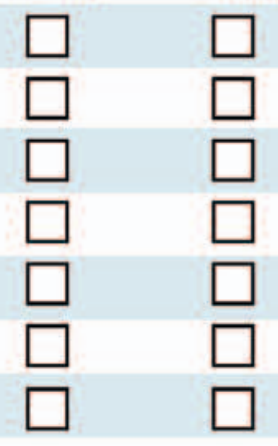

$\square$

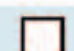




\section{Educational Activities and Professional Development}

11. Has the appraisal process altered the type of educational activity you participate in?

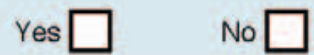

If yes, please indicate which activities you are now participating in as a result of appraisal:
i) Practice based learning
ii) Protected learning time events
iii) E-learning
iv) Attending courses

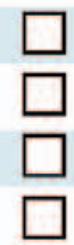

12. In comparison to the previous system of PGEA, the introduction of appraisal has benefitted my learning and development
Strongly agree

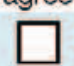

v) Distance learning

vi) Studying for further qualifications

vii) Other (please specify)

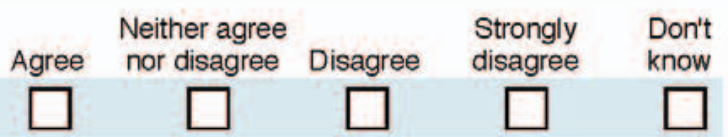

13. a) Has constructing a Personal Development Plan (PDP) influenced your learning?
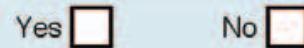

b) If yes, please describe in what ways:

Teaching and Training

14. Are you involved in formal teaching or training?

Yes

No (go to Q15)

If yes, has the appraisal process changed the way you approach teaching or training?

a) To the contribution you make to the education of registrars, students or colleagues

\begin{tabular}{|c|c|c|c|c|}
\hline $\begin{array}{l}\text { Not } \\
\text { at all }\end{array}$ & $\begin{array}{c}\text { In a } \\
\text { small way }\end{array}$ & $\begin{array}{l}\text { A fair } \\
\text { amount }\end{array}$ & $\begin{array}{l}\text { Quite } \\
\text { a lot }\end{array}$ & $\begin{array}{l}\text { A great } \\
\text { deal }\end{array}$ \\
\hline
\end{tabular}

b) In developing your skills as a teacher

Relationships with Patients
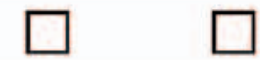

$\square$

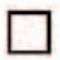

15. Has GP appraisal influenced how you interact with patients?

Not at all

$\square$

\section{In a} small way

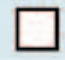

b) Reviewing the way you deal with complaints

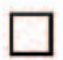

$\begin{array}{ccc}\begin{array}{c}\text { A fair } \\ \text { amount }\end{array} & \begin{array}{c}\text { Quite } \\ \text { a lot }\end{array} \\ \square & \square & \square\end{array}$

\section{Working with Colleagues}

16. Has your GP appraisal changed the way you
work with colleagues?
a) Communicating with colleagues
b) Clarifying responsibilities in the team
c) Being aware of the performance of colleagues
d) Supporting other members of the team if
performance issues occur
e) Delegating care to other health care workers
L




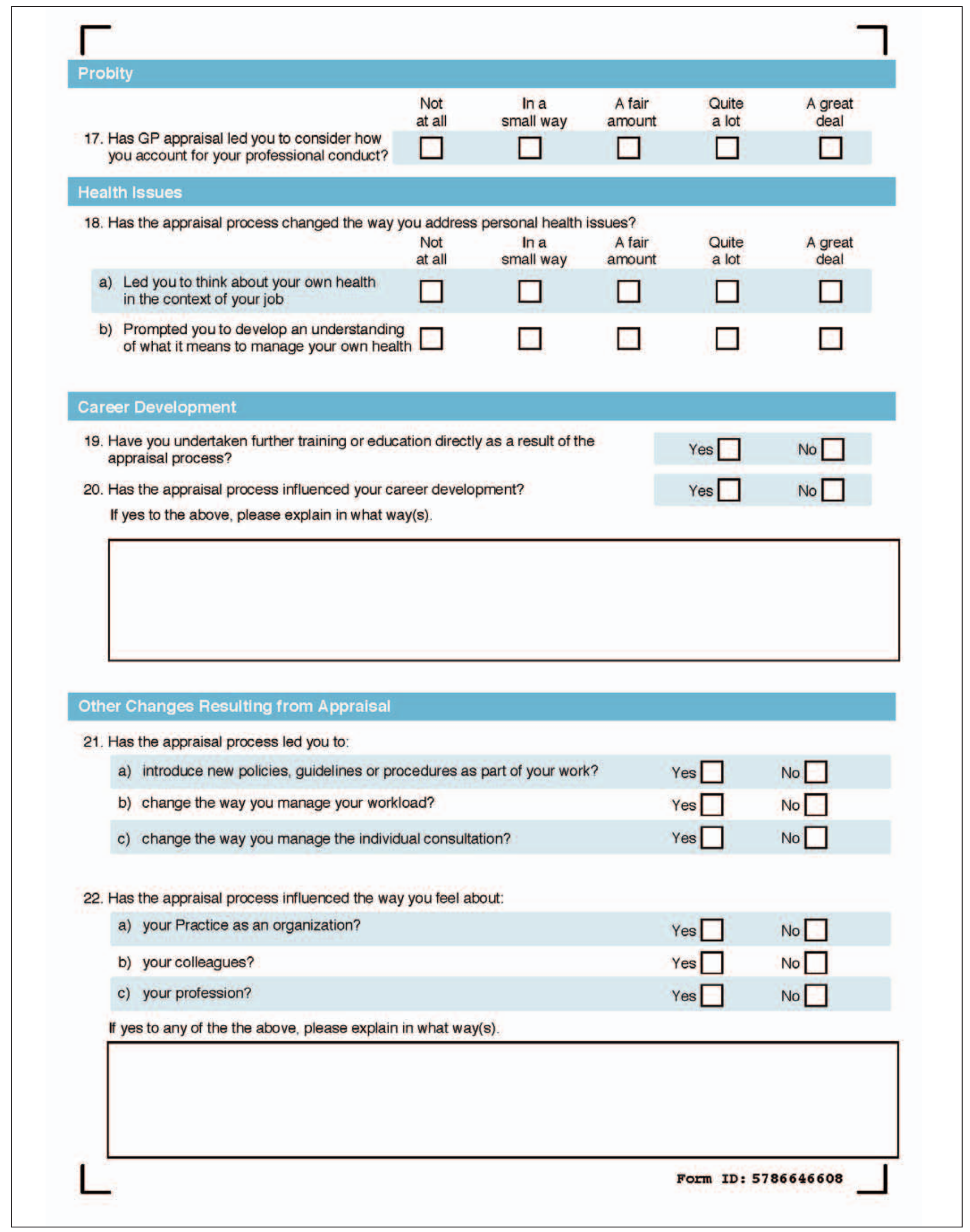




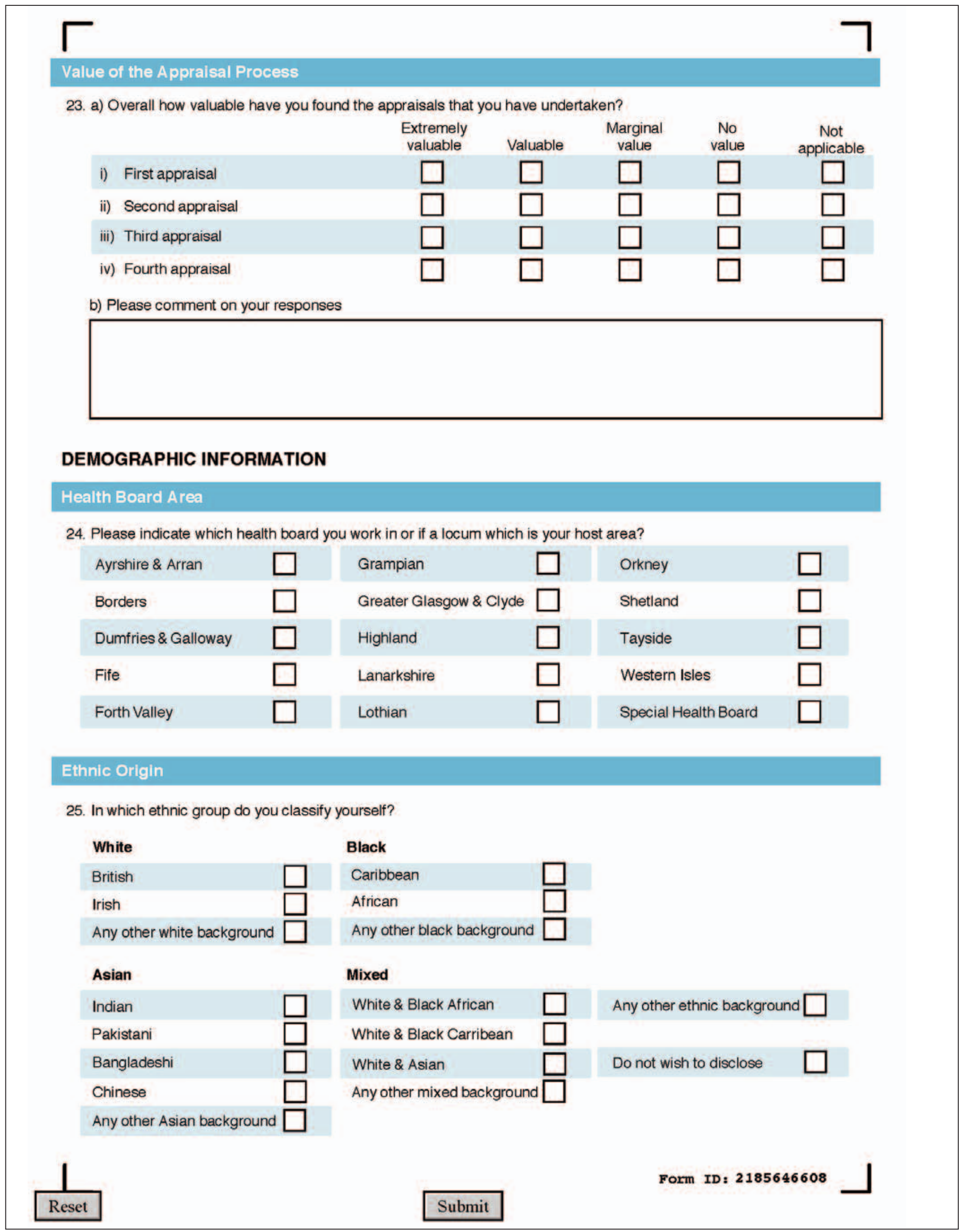

